\title{
A CASE REPORT OF LOW GRADE MALIGNANT PERIPHERAL NERVE SHEATH TUMOUR
}

K. Sampath Kumar¹, A. Rajesh Kumar², M. Neeraja ${ }^{3}$, P. Venkata Ramananababu ${ }^{4}$

\section{HOW TO CITE THIS ARTICLE:}

K. Sampath Kumar, A. Rajesh Kumar, M. Neeraja, P. Venkata Ramananababu. "A Case Report of Low Grade Malignant Peripheral Nerve Sheath Tumour". Journal of Evolution of Medical and Dental Sciences 2015; Vol. 4, Issue 05, January 15; Page: 872-878, DOI: 10.14260/jemds/2015/124

ABSTRACT: Malignant nerve sheath tumours [syn: Neurogenic sarcoma, Neuro fibro sarcoma] comprise approximately $5 \%$ of all soft tissue sarcomas. Only 8to15\% of these tumours arises in Head and neck region. Commonest sites in head and neck region are lateral skull base or along the course of cranial nerves. These tumours in sino nasal region are extreme rare. In this article we report a rare case of low grade MPNST. The tumour was resected by medial maxillectomy via modified Denker extended maxillary anterior antrostomy, resected tumour Histopathological examination and immunohistochemistry study reported as low grade MPNST and negative for s-100 protein. Patient was relieved from symptoms and followed for 18 months.

KEYWORDS: Low grade MPNST. Neuro fibromatosis type 1. Medial Maxillectomy.

INTRODUCTION: Malignant peripheral nerve sheath tumour (MPNST) is cancerous form, origin from peripheral nerve sheath cells (Schwanns cells of nerve sheath) or from benign peripheral nerve sheath tumour called Neurofibromas. MPNST also known as neurogenic sarcoma/malignant neurilemmoma /malignant schwannoma. ${ }^{\{1\}}$

MPNST occurs most commonly in deep soft tissue along the nerves that runs from the buttocks to legs, neck to arm, or with in pelvis. The primary neurogenic tumours of the nose and paranasal sinuses are rare, accounting only 5\%of all neural tumours of the head and neck.\{2\} Most of the MPNST are high grade and have high aggressive clinical course. However 18\%of MPNST are reported as low grade. ${ }^{\{3\}}$ In this article we describe a case of low grade malignant peripheral nerve sheath tumour of the paranasal sinuses, and we review the literature, clinical presentation, management, histopathology and prognosis of this tumour.

CASE REPORT: A 45 yrs old women presented in our Dept. on March 2013, by given chief complaints of Right nasal obstruction- since 2yrs, which is continuous and progressive, there is no aggravating and relieving factors as Nasal polyps. She had been assessed elsewhere as Nasal polyp. The patient also had intermittent mucoid type nasal discharge from Rt. nostril, headache, Anosmia and left nasal obstruction since 6 months. CT scan of PNS done, reported as expansile mass in rt. nasal cavity extending to choana backwards and rt. nares forwards, deviation of septum towards left. The osteomeatal unit on right was markedly enlarged and all of the rt. sided sinuses are completely opaque [Fig. 2, 3]. DNE done under L. A. revealed that rt. nasal cavity was occluded by firm, greyish pink mass-which is soft consistency, insensitive and bleeds on touch[fig- 1 ] and biopsy taken, send for HPE. Biopsy reported as Low grade peripheral malignant nerve sheath tumor and planned for Medial Maxillectomy. 


\section{CASE REPORT}

OPERATION: Under general anaesthesia the patient underwent right medial maxillectomy via Denker extended maxillary anterior antrostomy approach.[Fig. 4 ] The tumour was removed along with the lateral nasal wall, which was incised from below, the inferior turbinate to above the middle turbinate and anteriorly at nasal valve area. The sinonasal cavity packed with soframycin soaked ribbon gauge and suturing done in layers by $3(0)$ vicryl and $3(0)$ silk. The cavity pack removal done after 72 hours [Fig. 6] and suture removal done after 7 days.

Macroscopic View: the removed tumour is soft tissue mass measuring $2 \times 1 \times 0.5 \mathrm{~cm}$, greyish brown homogenous areas. On cut section larger bits shows thin capsulated, grey brown and greyish white areas are shown.[Fig. 5].

Microscopic View: excised tissue shows pseudo stratified ciliated epithelium with squamous metaplasia. In subepithelial tumour tissue composed spindle to elongated cells arranged in bundles of sheath, at places there is more cellularity with nuclear atypia, areas of haemorrhage, focal areas of necrosis [Fig 7, 8, 9].

The patient returned for follow up on $2^{\text {nd }}, 4^{\text {th }}$ weeks, $3^{\text {rd }}$ and $6^{\text {th }}$ month. Patient is well without any complications. Her airway was patent and no recurrent, residual tumour were found on DNE.

DISCUSSION: Malignant peripheral nerve sheath tumour arises from a peripheral nerve or intrinsic nerve sheath differentiation. They compraise approximately $5 \%$ of all malignant soft tissue tumours. Most of MPNST are high grade and have highly aggressive in its clinical course. However 18\%MPNST were reported as lowgrade, which are less aggressive.\{2\} Most are derived from Neurofibromas, often the plexiform type or Neurofibromatosis type 1 (NF1) or arise denovo in normal peripheral nerves.\{3\}

Most of peripheral nerve sheath tumours of the nose and paranasal sinuses are arise from the ophthalmic and maxillary branches of Trigeminal nerve and its terminal branches, ${ }^{\{4\}}$ although it is often difficulty to identify exactly which nerve is involved. In nose and paranasal sinuses the commonest sites for these tumours are ethmoidal (57\%) and maxillary sinuses (54\%). ${ }^{\{5\}}$

MPNST generally occurs in adulthood between the ages of 20-50 years, no predilection for sex and race. $\{6\}$ Its clinical presentation differs according to the site involved, in this region most common symptoms are unilateral nasal obstruction, epistaxis, pain in facial area, and swelling of the facial and orbital region. $\{7\}$ Often presenting symptoms are mucopurulent rhinorrhoea, hyposmia, and headache.

The treatment of choice for low grade MPNST is wide surgical resection of tumour with negative free margins. ${ }^{\{8,9\}}$ Adjuvant radiotherapy in these cases found to improve local control and reduces local recurrence rate. In this case tumour clearance done by medial maxillectomy via denker extended maxillary antrostomy approach. This Technique provides excellent exposure. Regional lymphnodes clearance is unnecessary. ${ }^{99\}}$ The histological feature of MPNST are well known, presence of spindle cells with hyper cellularity, remarkable cytological atypia, increased mitotic activity and necrosis arranged in bundles or fasciles. Immunohistochemistry play important role in diagnosis. s-100 protein stain is positive in $96 \%$ cases to exclude fibrosarcoma. $\{10,3\}$ The diagnosis of low grade MPNST are not easy and depends on clinicopathological, histopathology and immunohistochemistry (s-100protein stain). In our study immunohistochemistry(s-100protein stain) is negative. 
Recurrence can be discussed in terms of local disease and distant metastasis of disease. The local recurrence rate of MPNST has been reported from 40-68\% in most of studies. 5 year survival has been reported to range from 16-52\%.\{11,12,13\} Longer survival has been correlated with complete surgical excision, tumoursize $(<5 \mathrm{~cm})$, histological grade of tumour (low grade). ${ }^{\{14\}}$

The role of chemotherapy and radiotherapy of this tumour is debatable. Adjuvant radiotherapy help to reduce rates of distant metastasis or overall survival rates. ${ }^{\{15\}}$ chemotherapy has been used in the treatment of high grade disease, unresectable, recurrent disease, and metastases cases. $\{9\}$

\section{CONCLUSION:}

1) Low grade MPNST are rare malignancies in sinonasal areas, it occurs as sporadically in patient with no known risk factors.

2) Typical presentation of sporadic MPNST is painless enlarge mass presented as nasal obstruction appeared as nasal polyp.

3) The prognostic factors for low grade MPNST are early detection, tumour size, complete wide excision of tumuour mass, histological grade and immunohistochemistry study for accurate diagnosis (s-100 protein is positive in $96 \%$ cases).

\section{REFERENCES:}

1. Haung. J; Johnson v; Zager. E.-Tumours of the peripheral nerves and plexuses: 2006: 8; 299-309.

2. Dublin AB; Dedo HH; Briget. WH - Intranasal schwannoma: Magnetic and Computed tomography appearance: Amj.otolaryngol-1995:16; 251-54.

3. Ducatman B. S. MPNST A clinicopathological study of 120 cases: cancer-1986:57; 2006-21.

4. Ross C; Wright E; Mosely. J; Rees. R. -Massive schwannomas of the nose and paranasal sinuses: south.Med.J: 1988:81; 1588-91.

5. Younis RT; Gross CW; Lazar RH -Schwannoma of the paranasal sinuses: case report and clinicopatholgical analysis: Arch otolaryngol Head and neck surg: 1991:117; 677-80.

6. Higo. R; Yamasoba. T; Kikuchi.s. -Nasalneurinoma: case report and review of literature: Auris Nasus Larynx - 1993:20; 297-301.

7. Mosharaffa TH; Kuppersmith RB; Porter JP; Donovan. DT -Malignant peripheral nerve sheath tumour of the Ethmoidal sinus: Arch otolaryngol Head and neck surg:1997: 123; 654-657.

8. Robitailley; Seemayer. TA - peripheral malignant nerve tumour involving paranasal sinuses -a case report and review literature: cancer 1975:35; 1254-58.

9. Marwel. JB; Parke. RB. Jr - Malignant schwannoma of the nasal cavity: otolaryngol Headnecksurg: 1990: 102; 409-12.

10. Scheithauer. B. W; Woodruff.JM - primary malignant tumour of peripheral nervous system: Atlas of tumour pathology -3 $3^{\text {rd }}$ series 1999; 303-72.

11. Hurban RH; Senie RT; Woodruff. JM - MPNST of the buttock and astudy of 43 cases: cancer 1990, 66[(6)] 1253-65.

12. Kourea HP; BM. Leung DH; Lewis. JJ; woodruff. JM -Sub diaphragmatic and intra thoracic paraspinal malignant peripheral nerve sheath tumour clinicopathological study of 25patients and 26 tumours;cancer 82[(11)], 1998;2191-203. 


\section{CASE REPORT}

13. Wong. ww; HT Scheithauer BW; Schild SE; Gunderson LL -malignant peripheral nerve sheath tumour: analysis of treatment outcome. Int. J. Radiatoncol bio phys 1998, 42(2); 351-60.

14. Cashen DV; P. R. Raskin; Hornicek. FJ; Gebhardt MC; Mankin. HJ -Survival data for patients with malignant schwannoma: Clinorthoprelat res: 2004; 426; 69-73.

15. VRASS; KJ Nielsen. OS.; Sneppen. O.; Jurik. AG.; Jensen. Om-prognostic factors in soft tissue sarcomas- Eur. J. cancer; 1998, 34 (12); 1876-82.
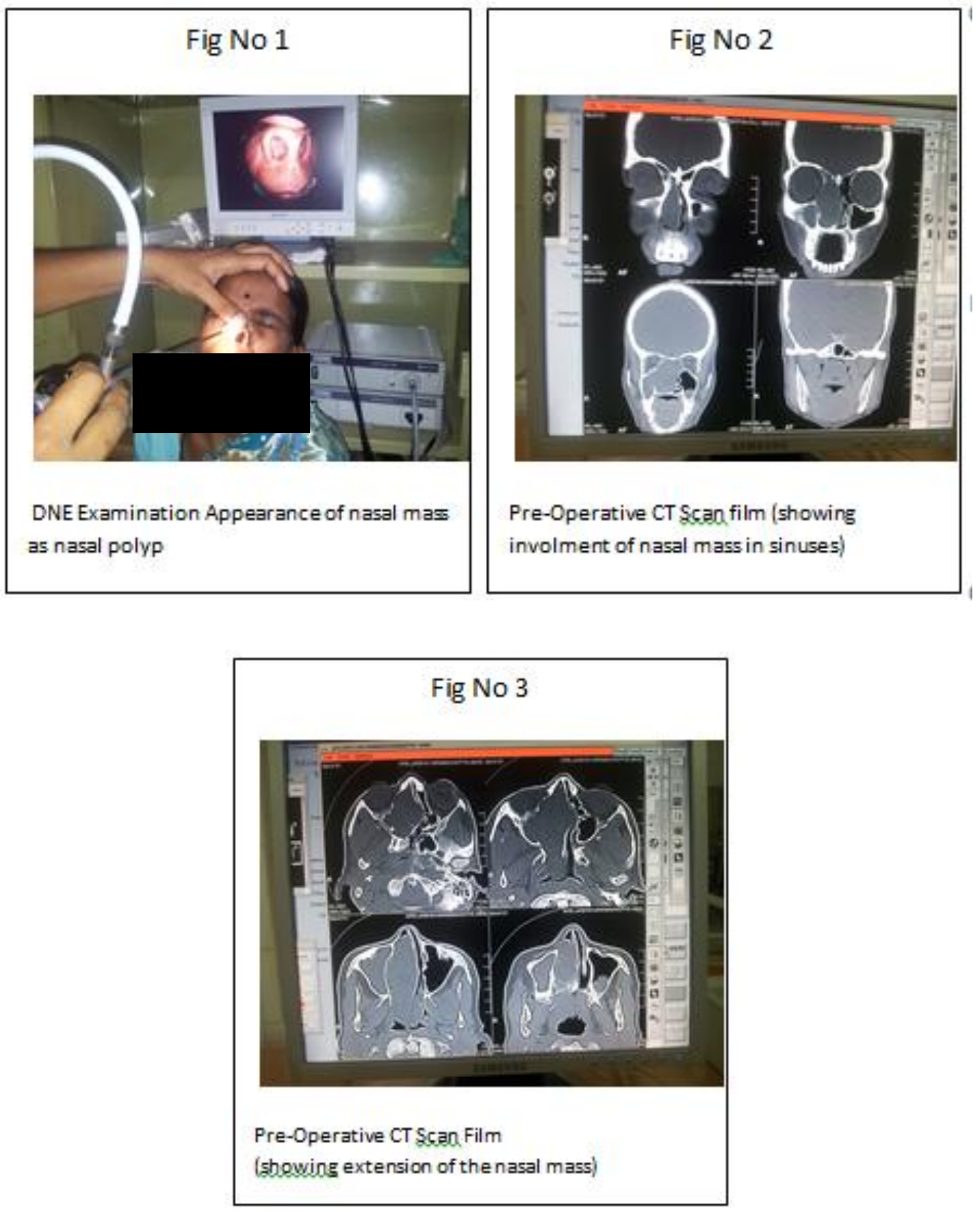


\section{CASE REPORT}
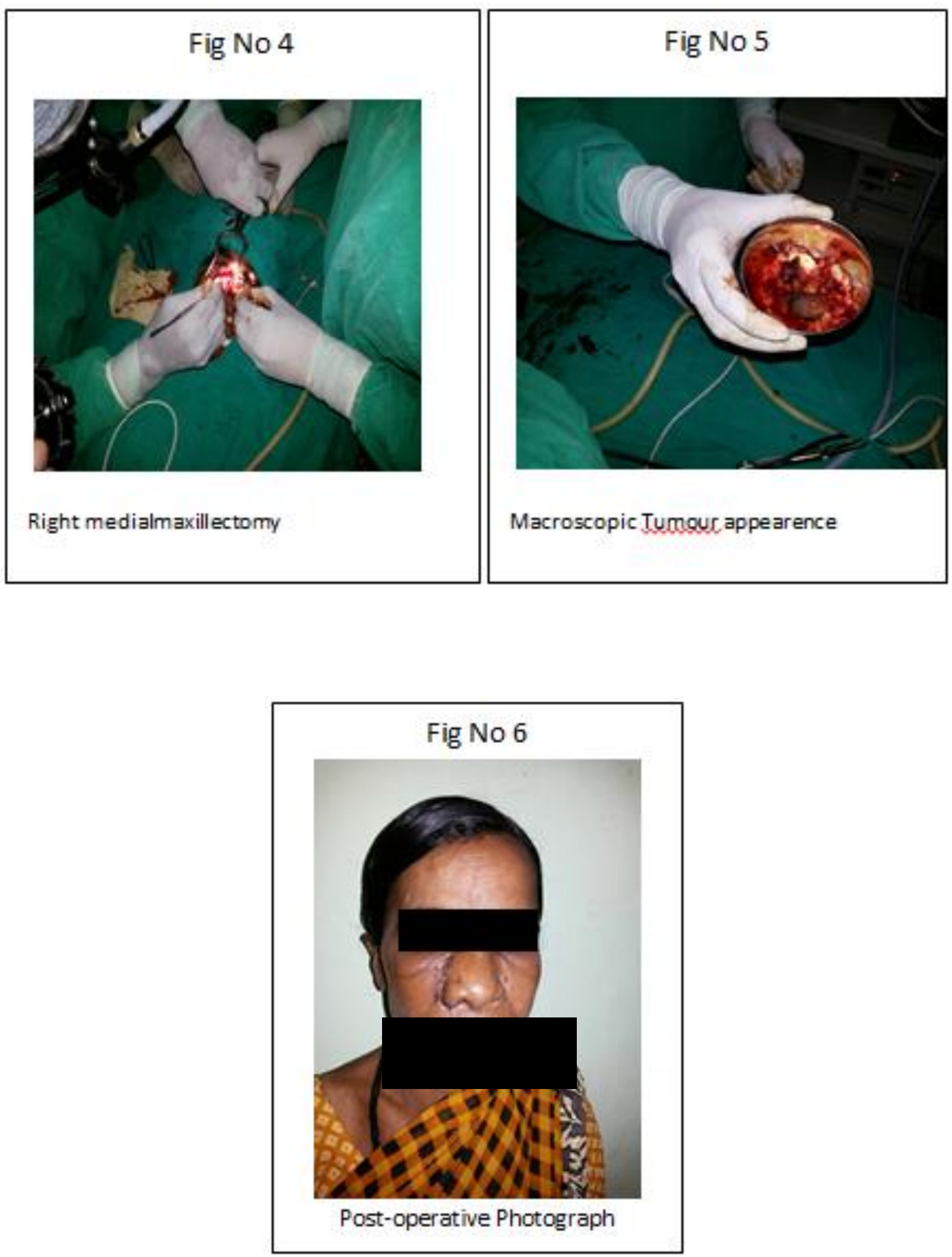

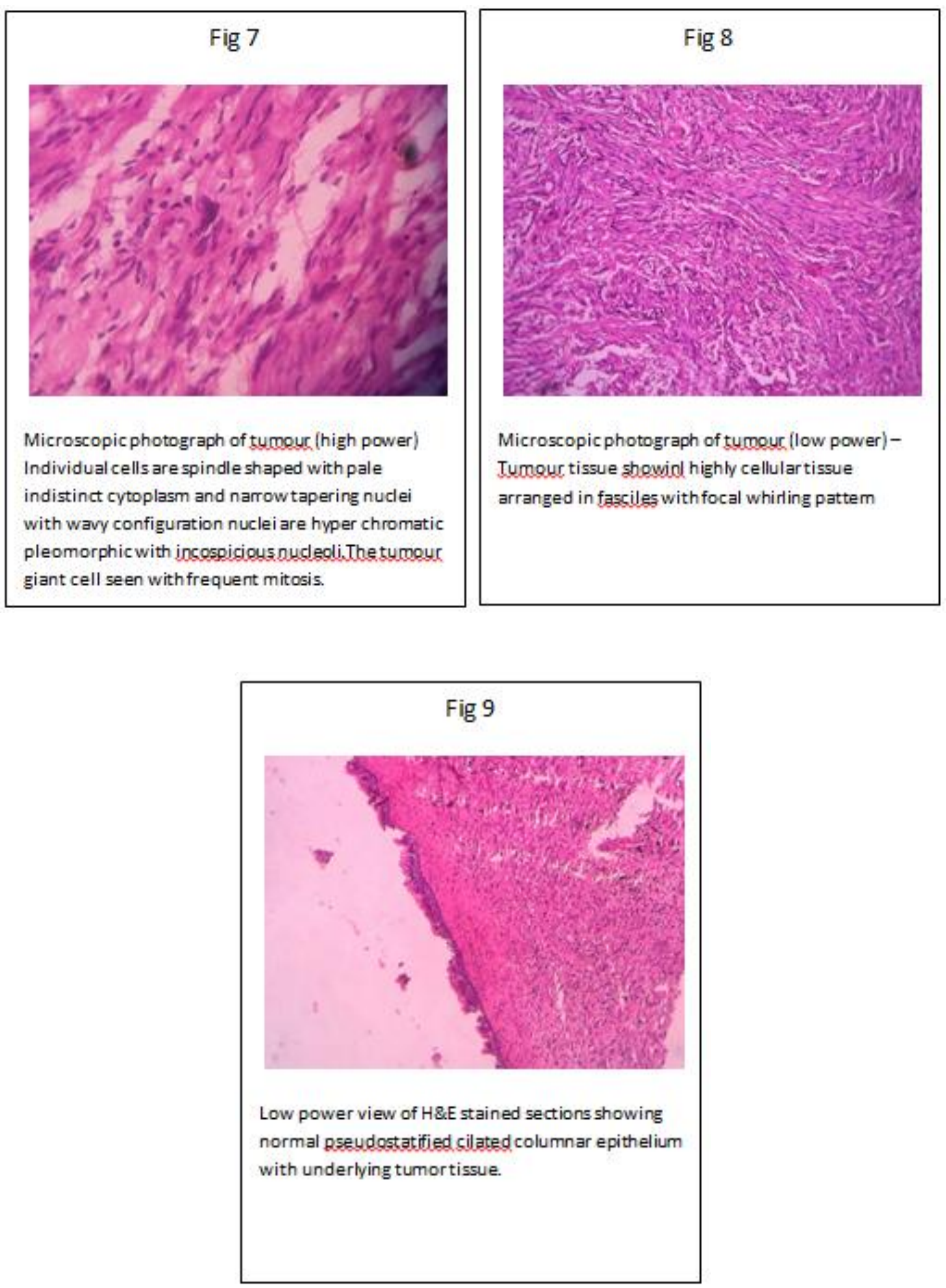


\section{AUTHORS:}

1. K. Sampath Kumar

2. A. Rajesh Kumar

3. M. Neeraja

4. P. Venkata Ramananababu

\section{PARTICULARS OF CONTRIBUTORS:}

1. Associate Professor, Department of ENT, Government General Hospital, Government Medical College.

2. Assistant Professor, Department of ENT, Government General Hospital, Government Medical College.

3. Professor and HOD, Department of Pathology, Government General Hospital, Government Medical College.
4. Associate Professor, Department of Pathology, Government General Hospital, Government Medical College.

\section{NAME ADDRESS EMAIL ID OF THE CORRESPONDING AUTHOR:}

Dr. K. Sampath Kumar, Department of ENT, Government General Hospital, Anantapuramu-515001, A. P.

E-mail: dr_rajesh1980@yahoo.co.in

Date of Submission: 29/12/2014.

Date of Peer Review: 30/12/2014.

Date of Acceptance: 06/01/2015.

Date of Publishing: 14/01/2015. 